\title{
Community medicine: future imperfect?
}

\author{
J. STUART HORNER \\ From the Croydon Area Health Authority
}

SUMmaRY The development of community medicine is seen in historical perspective and found to be a redirection of preceding trends rather than the development of new concepts. The current problems of the specialty are reviewed and found to be due to erroneous perceptions of its role by many doctors, to the specialty's present preoccupation with its academic purity, and to the failure to provide within the National Health Service the resources that were vital to the functions it was asked to perform. It is argued that the essential skill of community physicians is epidemiology, which must be applied within the management process of the National Health Service to enable it to adapt itself to the needs of changing disease patterns. It must also be applied to the prevention of disease and this will necessarily involve the community physician in much wider social problems than the provision of medical care services. This second responsibility may well prove to be the more crucial in the longer term.

The artificial distinction between the medical care of individual patients and the provision of medical advice to groups of healthy people is, in historical terms, a recent development in medicine which owes more to the development of health care in the last century than to any rational division of medical responsibilities. John Snow, a pioneer epidemiologist of the nineteenth century, would have considered it in no way incongruous to be remembered both as the anaesthetist to Queen Victoria during two of her confinements, and as the man who removed the handle of the Broad Street pump in Soho as an epidemic of cholera was affecting the surrounding district. Eminent practitioners in clinical medicine have followed the pioneering example of John Simon, the first Medical Officer of Health to the City of London, and entered the field of public health or social medicine at the peak of their clinical careers, so demonstrating the essential unity of population medicine and clinical medicine which Hippocrates set out for his students.

The Public Health Act of 1872 , with its extension of the office of medical officer of health to all parts of the kingdom, created a focus around which local resistance to the vested interests which threatened the health of whole communities could be mobilised, and so assisted the great sanitary movement of the day. Yet it marked the beginning of a division between doctors whose primary responsibility was to individual patients and doctors whose primary concern was community action to ensure that every person had an opportunity to live a healthy life free from the ever present risk of death and disease. As the present century dawned so the role of the medical officer of health as an independent critic began to be eroded by his progressive involvement in the administration of health care services. As each new service was identified for priority and improvement it was added to his responsibility, until most hospitals run by public authorities were transferred to his care in 1929. His wide powers gave him considerable authority both within the profession and outside it, but his administrative duties steadily reduced his professional expertise in medicine itself and particularly his capacity to criticise the system of which he was now an identifiable part. The new National Health Service in 1948 further divided doctors concerned with population groups into those who remained primarily administrators of hospital services and those who remained as medical officers of health in charge of much reduced departments. The latter group concentrated on what was left, often rebuilding with some distinction the preventive health services and developing existing services for the medical care of patients in their own homes. It was a time of optimism, although the undoubted success of many leading practitioners tended to overshadow two disturbing long-term trends. Firstly, recruitment of doctors into the administrative echelons of the National Health Service was becoming increasingly difficult. Secondly, the power of local authorities themselves was steadily ebbing away as more and more decisions were taken at central government level. These trends are apparently not unique to this country ${ }^{1}$ and must be taken into account in proposals for the future. 
The insistent demand for the integration of the tripartite National Health Service inevitably raised doubts about the future role of medical officers of health. Prevention was now being seen in broader terms and extended to the mobilisation of the health care services to provide both early detection of existing but undisclosed ill health and continuing care for the chronically handicapped. Still separated from their clinical colleagues, all doctors concerned with population groups realised that they were using the same basic skills and that these required a similar core of knowledge and training, recognisable and distinct from that in other medical specialties. In 1972, the three Royal Colleges of Physicians in the United Kingdom created a joint Faculty of Community Medicine, and two years later community physicians were formally recognised within the management structure of the reorganised National Health Service. The name of the specialty was a compromise because none of the existing titles was considered suitable. Nevertheless, its ambiguity, which seemed such an attraction at the time, has allowed many to walk under its banner who had very different conceptions of the nature of the specialty. ${ }^{2}$ It has been even more difficult for those outside the specialty to recognise its collective perception of itself and to compare that with their own preconceptions of what it should be. So, while everyone seemed to be agreed that the medical officer of health must go, there was far less agreement about the type of doctor who should replace him. Descriptions by community physicians of their new roles have reflected this uncertainty, ${ }^{3-6}$ and even the theoretical concepts developed during the process leading up to reorganisation evidently differ from present reality. ${ }^{7}$ Recognising the damage to the credibility of the specialty which has been caused by these uncertainties, the Conference of Community Medicine in 1977 resolved to set up, in conjunction with the Faculty of Community Medicine, a working party to review the expectations of the specialty and the extent to which these were being achieved in the reorganised National Health Service. Its report ${ }^{8}$ published last year emphasised that many of the changes on which the specialty crucially depended have simply not occurred, and community physicians have been given too many responsibilities for the available manpower and support services allocated to them.

ERRONEOUS CONCEPTS OF COMMUNITY MEDICINE

Whenever the precise duties of a person are unknown the usual response is to identify a convenient stereotype of the post he holds in an effort to gain a perception of his work. There is good evidence that many doctors are employing a variety of stereotypes $\underline{\overline{0}}$. in an attempt to understand the role of community $O$ medicine and some are worth exploring in detail. Outdated public health teaching provided in some medical schools in the relatively recent past provides a common stereotype of the community physician as the principal protagonist in mankind's battle with $\mathrm{a} \frac{\mathrm{T}}{\Phi}$ wide range of animal pests. The extermination of rats $\triangleq$ and mice, cockroaches and flies, and disease-carrying? pigeons are all assumed to fall within the community $\overrightarrow{\vec{F}}$ medicine remit. In fact these duties have been carried $\stackrel{\text { ? }}{\circ}$ out by staff under the control of environmental? health officers for many years, and the reorganised $\frac{\bar{O}}{\overline{0}}$ National Health Service merely regularised the $\frac{\text { }}{\sigma}$ position by removing the community physician from $\Omega$ his managerial accountability, but not his advisory responsibility, for these duties. Infectious disease, $\vec{O}$ however, refuses to go away and a worrying organisational gap is now developing in many areas $\vec{\omega}$ as community physicians have moved away from their residual responsibilities to local government.

The second stereotype popular among doctors is a $\vec{\omega}$ semantic confusion. If a hospital nurse works withit + an institution and a community nurse outside it, the in logic a general physician works in a hospital and community physician outside it. Many mediciㅇㅇㅢ officers of health had undertaken a leadership role the domiciliary care services, and the increasing emphasis upon these services at the very time whe्gु the newly defined specialty was organising itseiff $\vec{\bullet}$ served to confirm the perceptions that wege emerging. In fact the medical officer of health had been progressively stripped of his responsibilities before reorganisation, and the transfer of the community nursing staff on the appointed day was the final step in a continuing process. 'Battered by fragmentation of his department, the medical officer $\cong$ of health was destined either for extinction or for $\overrightarrow{\overrightarrow{0}}$ transformation. Both in effect were accomplished by 3 the reorganisation of the National Health Service'. ${ }^{2}$

The emphasis during the reorganisation period on monitoring and evaluation of work done created a far $\frac{}{\infty}$ more worrying stereotype and one which the profession was overwhelmingly determined it did not $\overline{0}$ want. The return of community physicians to the management of the hospital services immediately 8 raised the question of their relationships with clinical $₹$ colleagues. Were they to be some form of medicalo superintendent which the profession thought it had destroyed 25 years before? Were they to be some o modern gauleiter* with an unacceptable degree of control over the way hospital doctors discharged $\sigma$

\footnotetext{
* A gauleiter was literally a region leader in Nazi Germany. The $\omega$ country was divided into 32 regions (gaue) for the purposes of $\sigma$ party organisation.
} 
their clinical duties? It may not be entirely unrealistic to suggest that it was this fear which attracted such hostility to the specialty, and still accounts in no small part for the suspicion with which its activities are viewed. There is increasing public concern about the apparent lack of accountability by doctors for management failures in the provision of clinical services, and some independent observers have urged more positive action by doctors within the management structure. ${ }^{9}$ Although this stereotype is firmly rejected by the specialty, the profession needs to pay more attention to allaying public anxiety on the point if it is not to create the very solution it firmly rejects.

A more comfortable stereotype for many doctors represents the community physician as a failed clinician who spends his time ineffectually in unnecessary attendance at useless committees. The disenchantment of doctors with management and the bureaucracies of health care which has become so evident since the reorganisation of the National Health Service has inevitably led to criticism of the community physician, who is identified with the despised bureaucratic structure and who was actually created by the complex management processes introduced at the time of reorganisation. As long as the artificial distinction between clinical practice and population medicine is maintained, and as long as the profession ranks the two in their present order of importance, the community physician will find it difficult to overcome such a stereotype. In order to discharge his responsibilities in an effective way the community physician must be involved in the management process. The profession has everything to gain from a firm insistence that community medicine is an essential part of its overall contribution to the health of the nation, and much to lose from its rejection of community physicians as second class doctors who have been seduced by management.

\section{PROBLEMS WITHIN THE SPECIALTY}

Even within the specialty there are difficulties in defining its real role and purpose. Although some of these are really questions of emphasis rather than fundamental differences about direction, they nevertheless indicate the continuing debate about what the specialty is seeking to achieve. It is difficult to avoid the conclusion that some of the specialty's deepest wounds have been self-inflicted.

The Society of Medical Officers of Health produced a report in 1966 which largely determined the broad direction of the specialty in the future. Seizing a rare opportunity, the report made proposals which ultimately led to the creation of the Faculty of Community Medicine. ${ }^{2}$ Yet many could see no purpose for such a society once the faculty had begun its work, and clearly such an antiquated title had to be changed. Unable to agree whether other professions should be included in its membership, and faced with a near-disastrous internal reorganisation which effectively destroyed its most successful component, the renamed Society of Community Medicine continues an existence which is a pale shadow of its former self. Meanwhile, community physicians formed themselves into a host of special organisational groupings the purpose of which seems more concerned with providing mutual support in daily tasks than with extending the broad frontiers of the specialty.

The principal problem for the specialty has been whether its practitioners see themselves as administrators or practical epidemiologists. Some would argue that they are free-standing consultants providing epidemiological support to colleagues in the hospital service. They see no basic difference between this specialty and any other medical specialty, and they are suspicious of any suggestion that a managerial role is also involved. Others see themselves primarily as medical administrators whose role within the organisation inevitably separates them from clinical colleagues but whose involvement in resource allocation creates an opportunity to apply medical skills and health information within the management process itself. The specialty's training programmes have rightly emphasised basic epidemiological and statistical techniques but have insufficiently stressed the application of such skills within the management process itself, or to the wider aspects of disease control within a community.

In order to create a new specialty, with responsibility for its own training, community medicine had to demonstrate the nature of its special skills, to show that no other specialty could effectively lay claim to them, and to distinguish itself from apparently related specialties. Those responsible for the foundation of the faculty accomplished these tasks most expertly but surrendered one very significant hostage to fortune. Some community physicians did practice clinical medicine but not usually of a sufficiently specialised nature to justify special training in a separate specialty. Some clinicians did practice epidemiology but not as a major component of their work. This overlap created a potential hazard to the independence of the specialty, and the faculty took great care to emphasise that community physicians practised medicine on groups and not upon individuals. ${ }^{10}$ This crucial decision has had several damaging effects. Firstly, many sympathetic clinicians have been excluded from the faculty itself; 
secondly, a new generation of doctors interested in practising clinical epidemiology has begun to question the relevance of the faculty's training programme to their specific needs; and, thirdly, it has tended to confirm the view of many clinicians that community physicians have opted out of clinical responsibility. A recent survey ${ }^{11}$ showed that a majority of younger members of the specialty considered that this decision should be reviewed.

Moreover, the insistence that clinical practice forms no relevant part of community medicine practice has meant that the faculty has been unable to contribute practical support to the community health doctors who are primarily clinicians and with whom community physicians have traditionally been associated. This group of doctors, whose training needs have been woefully neglected for far too long, includes a number who were founder members of the faculty and many whose formal postgraduate education has been in community medicine. It would be wrong to create another specialty for this group of doctors but it is difficult to see any existing specialty into which they can currently be absorbed. A more positive approach to their future than the well-intended 'bon voyage' of the faculty's president ${ }^{12}$ offers advantages to all those concerned.

The specialty's current preoccupation with its purity looks daily more like a death wish than a serious attempt to find solutions to real problems which have beset its practitioners for a generation. The 'olive groves of academe' are no doubt very attractive but to remain too long within them is likely to potentiate the damaging division between the service component and the academic base which has bedevilled the specialty for at least 30 years. Moreover, there is a danger that outside observers may derive a very distorted picture of the work of community medicine and form erroneous conclusions ${ }^{13}$ about its nature and potential. Trainees within the specialty express increasing concern at the dichotomy between what is taught in some university departments and the work they are required to undertake in their service posts. A number of university departments have made great efforts to overcome this dichotomy and it should be remembered that it is not just service departments in the specialty which are denied essential support services.

Acheson $^{14}$ has raised another and perhaps more fundamental problem in community medicine. The present preoccupation of community physicians with the patching up of an ailing hospital treatment service has precluded them from the key role of providing epidemiological intelligence for the community as a whole. Instead of acting as the public sentinel watching for factors that would demonstrate causation of disease so that prevention could become a practical possibility, the community physician has left his post to deal with the more immediate problems of medical treatment. Eskin ${ }^{15}$ has argued that the community physician's present role gives him a unique vantage point from which to consider these wider matters, and it was interesting to note that the Royal Commission ${ }^{16}$ thought that some means should be found of replacing the annual review of the community's health provided by the Report of the Medical Officer of Health until 1974. Some have gone further and argued that this preventive role is the specialty's only future. ${ }^{17}$

\section{OTHER FACTORS}

It is perhaps not always recognised that there was never a time when community physicians were able to set up the departments they needed to carry out $\vec{\circ}$ the duties allocated to them in 1974. Transferred to new administrative bodies, sometimes in different parts of the country, many were denied even basic secretarial support, quite apart from the $\frac{\circ}{?}$ administrative services necessary to provide $\dot{\omega}$ adequate health information systems. It is not surprising, therefore, that most communit physicians have concentrated their efforts of maintaining previously existing services. Many were prepared to wait for better days but sadly the economic situation has become steadily more bleak Financial cutbacks and service retrenchment are now the orders of the day, while the profession as a whol $\vec{\oplus}$ has led the public hue and cry against the burgeonin bureaucracy. So what seemed at first minor irritants to be temporarily endured have become major permanent facts of life to which few can find a solution. Even the preventive services themselves are seen as convenient areas of economy to feed the apparently insatiable demands of hospital services.

Many community physicians have become involved in administrative matters particularly in connection with their clinical colleagues. Indeed, some $\mathrm{e}^{18}$ have argued that the contribution of community medicine lies in undertaking the administrative work for doctors which the Cogwheel ${ }^{19}$ structure was set up to carry out. There is no doubt that the very patchy effectiveness of the Cogwheel machinery, together with the very cumbersome medical advisory machinery set up by the profession, have imposed additional burdens on the specialty and weakened the authority with which community physicians can speak within the management structure. It is, however, difficult to see this work satisfying the career aspirations of the new generation of community physicians who appear to be attracted by its epidemiological approach and the particular philosophy that many practitioners adopt towards the promotion of health. 
In the light of this review it is hardly surprising that the specialty faces serious manpower shortages and recruitment problems. Suggestions that the present establishment may be overgenerous ${ }^{20}$ take little account of the fact that there has been a massive reduction in the number of doctors engaged in what may be broadly termed 'community medicine duties', particularly at local level, and there is increasing evidence that important duties are simply not being done. In some areas community medicine now contributes little more than a token presence, and proposals have been made ${ }^{8}$ to group the remaining community physicians into teams. The number of recruits needed to achieve replacement levels is not great and there are encouraging signs that doctors are being attracted into the training programmes and that more are likely to be attracted in the future. The major problem is to nurture the specialty through what is likely to be a long period of negative growth until the desired renaissance takes place. During this period the specialty will certainly have to review its approach to a number of the major issues outlined in this paper, and introduce major changes in its training programmes. The disenchantment manifest among many trainees in the specialty and their reluctance to follow the faculty's training programmes, together with the disturbingly high drop-out rate, are all signs which the specialty cannot indefinitely ignore.

Community medicine in the United Kingdom is therefore currently in a very depressed state and there seems little purpose in disguising that fact. Until the patient recognises that he is ill and accepts the need to receive appropriate therapy, improvement is unlikely. A clear recognition of the duties and priorities of community medicine both within the specialty and outside it is essential, together with the realisation that constructive conflict with clinical colleagues is an inevitable and indeed necessary part of the task. The specialty must also recognise that it is not going to be able to provide a uniform level of service throughout the country during this interim period so that some trade-offs between quality and quantity of service will have to be made.

THE NATURE OF COMMUNITY MEDICINE

The basic skill of the community physician which he brings to the health services is that of epidemiology. ${ }^{21}$ His study of disease is not as it affects individual patients but as it affects whole communities. He will study disease patterns and in doing so he will observe changes over time requiring adjustment by the health care services, and he will contribute to the understanding of control and prevention of individual diseases. It is not necessary for the aetiology of a disease process to be fully understood before the epidemiologist can identify contributory factors. He can suggest preventive measures in such circumstances with considerably more confidence than the clinician, who can never be completely sure of the extent to which his treatment has affected the outcome,$^{22}$ although both should take full advantage of carefully controlled trials. ${ }^{23}$

The application of epidemiological skills will inevitably give the community physician a pivotal role in the preventive strategies of the community he serves. The preventive services are beginning to show signs of chronic neglect since 1974. The administrative reorganisation in the National Health Service damaged them more severely than the hospital service, and their direct competition with treatment services for limited funds has not been to their advantage. This is not to imply that preventive services and high technology medical services are mutually exclusive alternatives. On the contrary, both are needed ${ }^{24}$ but a balance is required. Currently, available resources are loaded too heavily towards the treatment services.

The community physician's epidemiological skills will inevitably lead him to challenge existing work patterns in treatment services. The tremendous variations in the use of resources between different units should not be allowed to continue unless they can be justified in a more convincing manner than at present. Some of these differences seem to be related more closely to the particular practice of individual institutions ${ }^{25}$ than to the doctors themselves, so there is no reason why clinicians should feel threatened. Yet as the profession edges very slowly but most surely towards audit of clinical standards by the clinicians principally involved, many doctors do feel very threatened by the community physician. A challenge, however well-intentioned, is usually the prelude to conflict, and both groups of doctors must recognise this. Like knights at a mediæval tournament, however, the aim should be mutual respect and a better standard of future performance rather than an attempt to destroy the credibility of the other.

One cause for suspicion is the community physician's involvement in management but an equally vital role is to carry epidemiological intelligence right into the management structure and to use it to create positive management decisions. The gap between health service management practice in the United Kingdom and even basic management and analytic theory is little short of alarming, and it is essential that future decisions are based on adequate and accurate information. This must mean that the community physician will be involved in the planning process which is slowly and painfully creeping into the National Health Service. 
A study of disease in groups rather than in individuals will inevitably result in the community physician seeing problems in wider terms than medicine alone. He will develop a sociological perspective so that his further training will also embrace the discipline of sociology as well as statistics. He will see large hospital institutions in sociological terms and paradoxically he will exhibit a concern for the individual patient in such potentially deprived situations. The insights of this discipline will have shown the community physician how individuals become deprived in social systems and the effect of that deprivation upon their health. So the community physician's ultimate responsibility for the standards of care for individual patients in long-stay hospitals arises not from an organisational gap but from the very skills he brings to the assistance of his clinical colleagues.

The community physician's administrative skills are not those of some petty official satisfying the demands of an overwhelming bureaucracy. His postgraduate training in management, an essential corollary for an epidemiologist who wishes to apply his skills to achieve practical action, together with his sociological background, enable him to move within the complex health service network seeking to overcome the resistance to change inherent in any large organisation. The community physician's medical and epidemiological skills enable him to evaluate new trends in health care, thus providing necessary direction for the organisation and enabling short-term problems to be resolved in accordance with long-term objectives.

THE WAY FORWARD

The present uncertainty within the specialty of community medicine will not be resolved until there is a clear sense of direction and some of its inherent inconsistencies are faced and overcome. The Faculty of Community Medicine must take a more positive approach to the specialty and become more responsive to the realities which the large majority of its members face at service level. It cannot allow itself to be dominated by any group which attempts to represent its own particular interest as the totality of community medicine. In this paper it has been argued that epidemiology is the essential skill but epidemiology leading to practical action through close involvement in the management process and resulting in the development of preventive medicine strategies. All of these activities must be prominently identified in training programmes within the specialty. The community physician will have to return to his epidemiological look-out post. Draper and his colleagues are right to emphasise that the community physician will find his identity only when he rediscovers his responsibility for prevention. ${ }^{17}$ They are mistaken, however, when they suggest that this requires him to withdraw completely from the management of health care services. In order to be an effective critic the community physician must have a secure base. The profession is clearly unwilling to give community physicians the unqualified endorsement that would be necessary to provide them with a secure critical platform. Only health service management currently provides a sufficiently effective base to challenge the vested interests which threaten the health of communities today. ${ }^{28}$

Historical parallels are confusing. The amalgamation of public health responsibilities with those of the Poor Law in the nineteenth century resulted in 'the biggest setback that English public health ever suffered'27 but the 20 years in which medical officers of health were responsible for both treatment and prevention services are usually assumed to be the highest point in their evolution. The really significant advances, however, were made by locally based men of vision who were outraged by the conditions they saw around them and the effects of those conditions on the health of the majority of people. The community physician needs to recapture that vision. The health of people today is threatene by health hazards equally insidious in their effects and equally the product of powerful vested interests no more anxious to restrict their activities than theif predecessors. Community physicians should watch for opportunities to increase the awareness in societ of the major components of current ill health and t mobilise effective social action against the major contributory factors. It is not sufficient to reorientate the health care system towards a preventive philosophy. Present interest in this direction is a false dawn, bassed as it is on misleading economics rather than a genuine recognition of the issues involved. ${ }^{28}$

McKeown $^{29}$ has reviewed mortality trends in the last two centuries and has relegated the health care system to a very subsidiary role in the improvements which have occurred. Looking at society's current response to disease in this country, the epidemiologist will notice that a variety of different agencies are involved in a remarkably unco-ordinated way. The contribution that each makes to the control of disease is unknown and the extent to which the efforts of housing policies, education programmes, sanitary science, doctors and nurses are complementary to one another, and the extent to which they are frankly contradictory, is unclear. Both local and national politicians have to be made to understand that preventive health strategies involve governments and whole communities. Prevention is not just a matter of the individual's responsibility for his own behaviour. ${ }^{30}$ Government 
action to remedy the harmful influences which the individual cannot control is equally essential. Brenner $^{31}$ in a persuasive article has suggested a link between disease patterns and the cycles of economic activity, and clearly the control of such factors involves economic and political issues which are utterly dependent on central intervention.

At local level, community physicians will not only identify the factors responsible for disease but will also be seeking to co-ordinate and mobilise all the policies in the locality in an endeavour to control their effects. Many services remain the responsibility of local government and most community physicians find themselves excluded from the necessary corporate planning. This is ironic in view of the insistence by local government only six years ago that adequate medical advice should continue to be available to it. A new generation of community physicians is beginning to emerge which may not see the importance of links with a wide range of local government departments. This is certainly not a plea to return to local government: most medical officers of health were too preoccupied with running their departments to give a great deal of time to overall council policies. Yet if the objective of a co-ordinated preventive strategy is to be achieved, wider policies than those of the health care system will have to be involved. It is to this challenge that community medicine must urgently address itself if the community physician is to avoid following the medical officer of health rather more precipitately, and considerably less gloriously, into history.

This paper is a development of issues presented to the Joint Clinical Meeting of the British Medical Association in Hong Kong. I thank Miss D. Thear for her patient retyping of the many preliminary drafts.

Reprints from Dr. J. Stuart Horner, Area Medical Officer, Croydon Area Health Authority, Taberner House, Park Lane, Croydon CR9 3BT.

\section{References}

${ }^{1}$ McIntosh I. The Canadian Medical Officer of Health: a look at his future. Can J Public Health 1978; 69: 355-9.

${ }^{2}$ Jordan William S Jr. Medical Education and an emerging specialty within the reorganised NHS. New York: Springer, 1978.

${ }^{3}$ Department of Community Medicine, University of Manchester. What do community physicians do? Manchester: Unit of Continuing Education, 1978.

4Murphy FW. District community physician-activity analysis. Public Health 1975; 89: 261-2.
${ }^{5}$ Patey DGH. The district community physician in practice. Health Trends 1975; 7: 28-30.

${ }^{6}$ Davenport CM. A district community physician-the first 10 months. Public Health 1975; 89: 263-7.

${ }^{7}$ Donaldson RJ, Hall DJ. The work of the community physician in England. Community Med 1979; 1: 52-68.

${ }^{8}$ British Medical Association. Report of a Joint Working Party. The State of Community Medicine. London: British Medical Association, 1979.

${ }^{9}$ Department of Health and Social Security. Report of the Committee of Inquiry into Normansfield Hospital. Cmnd No. 7357. London: HMSO, 1978.

${ }^{10}$ Faculty of Community Medicine. Preamble to standing orders. London: Faculty of Community Medicine, 1976: iii.

${ }^{11}$ Acheson ED. Clinical practice and community medicine. Br Med J 1979; ii: 880-1.

${ }^{12}$ Brotherston J. Clinical Medical Officer. Br Med J 1979; i: 1427.

${ }^{13}$ Noren J. Alternatives for community physicians. Br Med J 1979; ii: 345-7.

${ }^{14}$ Acheson ED. Clinical practice and epidemiology: two worlds or one? $\mathrm{Br} \mathrm{Med} J \mathrm{1979}$; i: 723-6.

${ }^{15}$ Eskin $\mathrm{F}$. A challenge for the future-a positive approach to community medicine. Public Health 1978; 92: 186-9.

${ }^{16}$ Royal Commission on the National Health Service. Report. Cmnd No. 7615. London: HMSO, 1979.

${ }^{17}$ Unit for Study of Health Policy. Rethinking Community Medicine-towards a renaissance in Public Health? Report from a study group. London: Unit for Study of Health Policy, 1979.

${ }^{18}$ Cang S. Doctors and the NHS. Uxbridge: Brunel Institute of Organisation and Social Studies, 1978. (Document No. 2070).

${ }^{19}$ Ministry of Health. Organisation of Medical Work in Hospitals. First Report of a Joint Working Party. London: HMSO, 1967.

${ }^{20}$ Young $\mathrm{K}$. Future staffing in community medicine. $\mathrm{Br} \mathrm{Med}$ J 1977; i: $1173-4$.

${ }^{21}$ Acheson Roy M. Epidemiology and the community physician. Public Health 1975; 89: 97-102.

${ }^{22}$ Dollery C. The end of an age of optimism. London: Nuffield Provincial Hospitals Trust, 1978. (Rock Carling Monograph).

${ }^{23}$ Cochrane A. L. Effectiveness and Efficiency. Random Reflections on Health Services. London: Nuffield Provincial Hospitals Trust, 1972. (Rock Carling Monograph).

${ }^{24}$ Godber $G$. The scope and means of prevention. Health Educ J 1978; 37: 155-64.

${ }^{25}$ Griffiths M, Waters WE, Acheson ED. Variation in hospital stay after inguinal herniorraphy. $\mathrm{Br}$ Med J 1979; i: 787-9.

${ }^{26}$ Draper P, Best G, Dennis J. Health and Money and the National Health Service. London: Unit for the Study of Health Policy, 1976.

${ }^{27}$ Chave SPW. The Rise and Fall of the Medical Officer of Health. London: Department of Community Health, London School of Hygiene and Tropical Medicine, 1979.

${ }^{28}$ Draper P, Griffiths J, Dennis J, Popay J. The Royal Commission and prevention. Lancet 1979; 2: 425-6.

${ }^{29}$ McKeown T. The Role of Medicine: Dream, Mirage, or Nemesis? London: Nuffield Provincial Hospitals Trust, 1976. (Rock Carling Monograph).

${ }^{30}$ Morris JN. Social inequalities undiminished. Lancet 1979; 1: 87-90.

${ }^{31}$ Brenner MH. Mortality and the national economy. Lancet 1979; 2: 568-73. 